\title{
Muatan Keindonesiaan dalam Buku Bahasa Arab Kelas XI Madrasah Aliyah
}

\author{
Rijalul Ghifar Al-Fanani \\ Pendidikan Bahasa Arab, UIN Sunan Ampel Surabaya \\ rijalalfanani26@gmail.com \\ Kamal Yusuf \\ Bahasa dan Sastra Arab, UIN Sunan Ampel Surabaya \\ kamalinev@gmail.com
}

\begin{abstract}
This study aims to determine the Indonesian content of Indonesian culture in the XI grade Arabic book printed by the Ministry of Religion of the Republic of Indonesia KMA Number 183 of 2019. Language learning is inseparable from the influence of culture and the elements in it on the target language community, especially Arabic. This study is a qualitative study using a linguistic approach that focuses on Indonesian cultural content. The primary data source in the study was the Arabic book class XI of the Ministry of Religion of the Republic of Indonesia KMA Number 183 of 2019. The results of this study indicate that the Indonesian content of Indonesian culture contained in the Arabic book Madrasah Aliyah printed by the Ministry of Religion of the Republic of Indonesia number 183 in 2019 was only found. in chapter 6, the cultural elements contained in the Arabic book Madrasah Aliyah printed by the Ministry of Religion of the Republic of Indonesia number 183 in 2019 are identified that there are 6 that correspond to cultural elements including, a) religious systems and religious ceremonies, b) systems and social organizations, c) knowledge systems, d) arts, and e) technology systems and equipment.
\end{abstract}

Keywords: culture, Arabic, textbooks

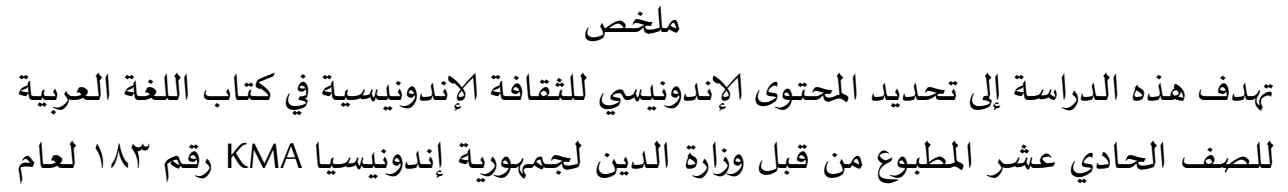




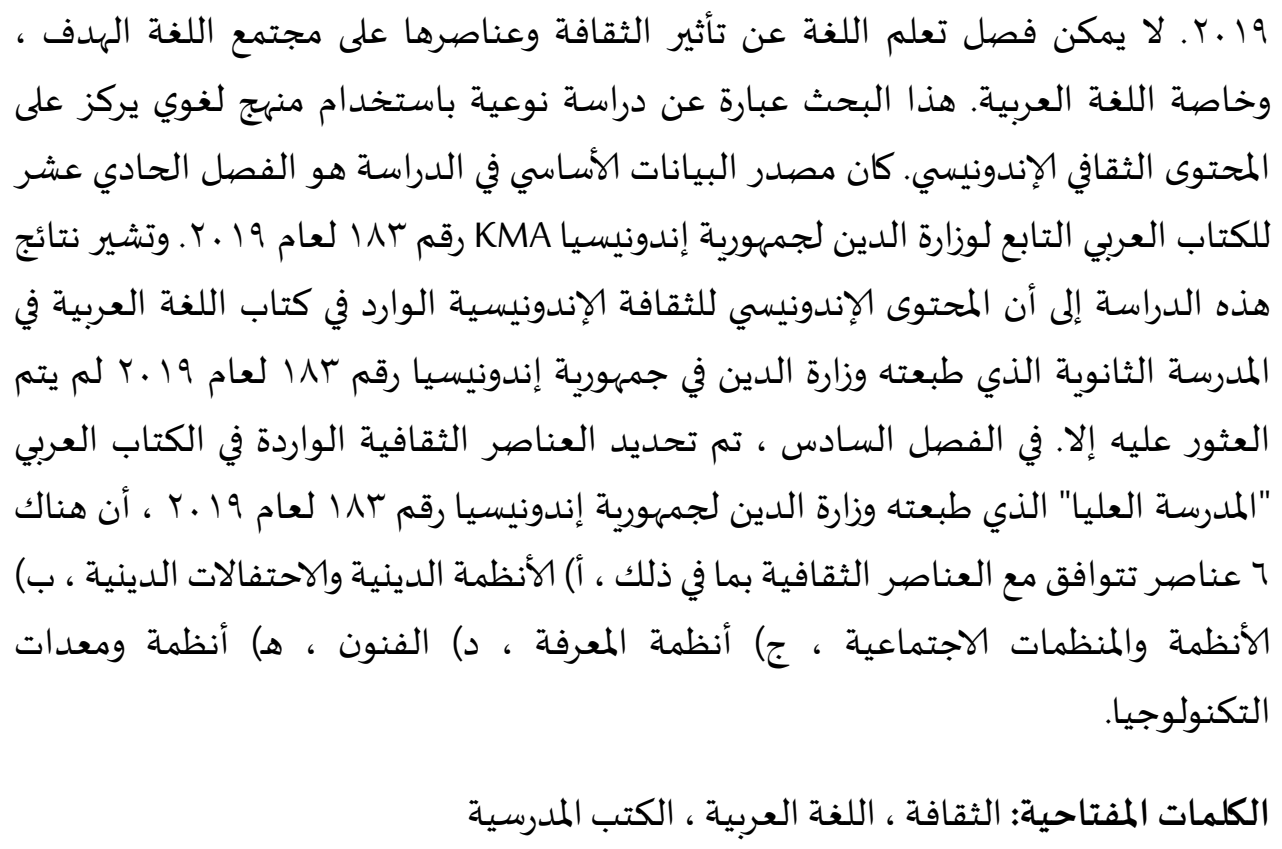

\begin{abstract}
Abstrak
Penelitian ini betujuan untuk mengetahuimuatankeindonesiaan budaya Indonesia dalam buku bahasa Arab kelas XI cetakan Kementerian Agama Republik Indonesia KMA Nomor 183 Tahun 2019. Adapun belajar bahasa tidak terlepas dari pengaruh budaya dan unsur-unsur yang ada didalamnya pada masyarakat bahasa sasaran khususnya bahasa Arab.Penelitian ini adalah penelitian kualitatif menggunakan pendekatan linguistik yang berfokus pada muatan budaya Indonesia. Sumber data primer dalam penelitian adalah buku bahasa Arabkelas XI Kementerian Agama Republik Indonesia KMA Nomor 183 Tahun 2019. Hasil penelitian ini menujukksn bahwa muatan keindonesiaan budaya Indonesia yang terdapat di dalam buku bahasa Arab Madrasah Aliyah cetakan Kementrian Agama Republik Indonesia nomor 183 tahun 2019 hanya ditemukan pada bab 6, Unsurunsur budaya yang terdapat di dalam buku bahasa Arab Madrasah Aliyah cetakan Kementrian Agama Republik Indonesia nomor 183 tahun 2019 teridentifikasi ada 6 yang sesuai dari unsur budaya diantaranya, a) sistem religi dan upacara keagamaan, b) sistem dan organisasi kemasyarakatan, c) sistem pengetahuan, d) kesenian, dan e) sistem teknologi dan peralatan.
\end{abstract}

Kata Kunci : budaya, bahasa Arab, buku ajar

\title{
A. Pendahuluan
}

Di Indonesia banyak sekali ragam agama dan bahasa. Selain itu juga terdapat ragam budaya di dalamnya yang sangat berpengaruh pada agama dan bahasa. Mayoritas penduduknya beragama Islam. Di dalam Al qur an itu sendiri bahasa yang digunakan adalah bahasa Arab yang mana bahasa tersebut 
menjadi bahasa asing bagi Negara Indonesia.Koentjaraningrat (2015: 2) berpendapat bahwa terdapat tujuh unsur kebudayaan, yaitu:

1. Sistem religi dan upacara keagamaan mencakup segala gagasan, pelajaran, aturan-aturan keagamaan, dongeng suci, riwayat tokoh, tata cara upacara.

2. Sistem dan organisasi kemasyarakatan mencakup struktur kasepuhan adat, rapat adat, kelompok janger, sistem perkawinan.

3. Sistem pengetahuan merupakan seperangkat unsur yang berkaitan dengan cara mengetahui hal yang perlu diketahui seperti: (a) alam disekitarnya, (b) flora ditempat tinggal masyarakat tertentu, (c) fauna atau binatang, (d) zat-zat mentah yang berada disekitar, (e) tubuh manusia, (f) sifat dan tingkah laku manusia, (g) ruang dan waktu.

4. Bahasa, Bahasa dari suatu suku bangsa selalu menunjukan berbagai variasi yang ditentukan oleh letak geografis dan bagaimana lingkungan sosial dalam masyarakat tersebut.

5. Kesenian, Seni tari, seni rupa dan berbagai folklore atau karya sastra yang disebarkan melalui komunikasi lisan ataupun dinyanyikan dan didendangkan.

6. Sistem mata pencaharian hidup, Misalnya pertanian, peternakan, sistem produksi, sistem distribusi antar bahan baku dan bahan makanan.

7. Sistem teknologi dan peralatan, Pembuatan alat-alat produksi, wadah, senjata, alat pembuat api.

Salah satu aspek budaya dalam berbudaya adalah keindonesiaan. Menurut Keraf (Marfai, 2013:35) Keindonesiaan menyangkut pengetahuan,pemahaman, dan adat kebisaan tentangadat manusaia, alam, dan memahamibagaimana relasi diantara semuapenghuni komunitas ekologis ini harusdibangun. Keindonesiaan harus bersifatkomunal secara kepemilikian dan tidakindividual.Oleh karena itu pembelajaran bahasa Arabsangat dipengaruhi beragam aspek yang pada hakikatnya adalah upaya mencari cara yang tepat dalam mengajarkan bahasa Arab agar para pelajar menguasai bahasa Arab yang secara umum dijabarkan ke dalam empat keterampilan berbahasa. 
Pada pengajaran bahasa terdapat dua pendekatan utama yaitu pendekatan formalis yang cenderung digunakan dalam waktu yang cukup lama, dan pendekatan fungsionalis yang baru berkembang pada abad ini. Pendekatan formalis mengutamakan pengajarannya bahasa lebih kepada bentuk-bentuk bahasa, sedangkan pendekatan fungsionalis lebih menekankan pada aspek fungsi. Sebagian kalangan ada yang berpendapat bahwa pengajaran unsur budaya pada bahasa bukanlah hal yang penting. Hal itu dikarenakan mereka menganggap bahwa pengajaran budaya membutuhan waktu yang lama dalam prosesnya. Padahal diberbagai pertemuan seperti seminar dan lainnya selalu membahas keterlibatan unsur budaya dalam pengajaran bahasa. Stern (dalam Yusari, 2012:121) menyatakan bahwa teori pembelajaran bahasa yang mengesampingkan persoalan-persoalan kebudayaan atau hanya menekankan aspek kebahasaan saja adalah salah.

Pengaruh ideologis dalam pembelajaran bahasa dapat dianalisis melalui teks yang digunakan sebagai bahan ajar. Selain itu, ideologi dalam pembelajaran bahasa dapat dikedepankan dengan menggunakan teori analisis wacana kritis dengan mengaplikasikannya dalam pembelajaran di buku teks.Ideologi bukan hanya dianggap sebagai bentuk adanya politik tetapi merupakan keyakinan budaya yang diwujudkan dalam bentuk materi dan praktik budaya. Oleh karena itu untuk membangun kesadaran bahasa kritis dalam pembelajaran bahasa bukan hanya mengajarkan struktur bahasa saja, melainkan menekankan pada pemahaman komunikasi untuk menyalurkan gagasan serta mengendalikan pemikiran dan tindakan seseorang melalui bahasa. Adapun belajar bahasa tidak terlepas dari pengaruh budaya dan unsur-unsur yang ada didalamnya pada masyarakat bahasa sasaran khususnya bahasa Arab.Pernyataan tersebut mengandung pesan bahwa seseorang yang mempelajari bahasa target tanpa memahami budayanya mengindikasikan orang "pandai berbahasa, tapi bodoh budaya” (Chick, 2009). 
Salah satu media pembelajaran yang digunakan dalam pembelajaran adalah buku teks atau buku ajar karena buku ajar mempunyai peranan penting dalam pembelajaran khususnya pembelajaran bahasa. Selain buku ajar yang mempunyai fungsi menjadi sumber utama dalam pengajaran, buku teks memiliki peranan penting dalam mengintegrasikan budaya dalam proses belajar mengajar. Hal itu menjadi penting dikarenakan buku ajar tidak hanya diajarkan untuk mendapatkan ilmu pengetahuan saja melainkan difahami dan muatan materi dalam buku ajar yang telah disajikan harus diaplikasikan dalam kehidupan sehari-hari. Warouw (2015) menjelaskan tentang keterkaitan antara bahan ajar yang diadaptasi oleh guru juga dipengaruhi oleh situasi dan lingkungan dimana pengajar tersebut berada

Buku teks memiliki peran penting dalam pembelajaran. Buku teks berperan dalam memberikan informasi tentang budaya masyarakat tutur. Stephen Billy Olajide menyatakan bahwa budaya tidak monolitik, setiap peneliti buku teks memiliki gaya dan sudut pandang yang berbeda dalam budaya menulis dalam buku teks yang ditulisnya. Oleh karena itu, penelitian ini mengasumsikan bahwa terdapat perbedaan budaya yang ditampilkan pada buku teks bahasa Arab untuk siswa non-bahasa Arab.Masalah yang muncul dalam pembelajaran bahasa Arab di Indonesia yang berkaitan dengan budaya dan bahasa khususnya pembelajaran dijenjang sekolah adalah kurangnya publikasikeindonesiaan budaya Indonesia dan Arab oleh pendidik dalam proses mengajar. Hal tersebut dikarenakan materi bahasa Arab yang sulit dipahami belum memenuhi materi yang dibutuhkan siswa. Hal ini perlu diperhatikan bahwa pengenalan budaya Indonesia dalam buku ajar bahasa Arab sangat penting selain kita menghormati dan menjunjung tinggi Negara kita Republik Indonesia, buku ajar juga bertujuan memudahkan pelajar (Indonesia) untuk memahami bahasa Arab dengan budaya mereka masingmasing.

Ada beberapa penelitian yang membahas tentang budaya seperti yang diteliti oleh Shofiana (2016) yang menjelaskan bahwa muatan budaya pada 
buku bahasa Arab Madrasah Aliyah kelas XI terbitan Kementrian Agama secaraumum mayoritas berisikan budaya dan dari budaya bahasa buku tersbut mayoritas berisikan budaya Arab. Ada juga penelitian lain yang diteliti oleh Fatma dkk (2020) yang membahas bahwa al-Kitab fi Ta'allum al'Arabiyyah dan al-'Arabiyyah bayna Yadaik mewakili perempuan dan posisi mereka dalam perkawinan dan masyarakat dengan cara multiperspektif.Selain itu juga ada penelitian lain dari Nurhidayati (2019) menjelaskan bahwa buku ajar bahasa Arab berbasis keindonesiaan budaya solo keseluruhan aspek kelayakan buku adalah 84,49 berada pada rentangan 71-85 mencapai skala 3 dengan kategori layak untuk digunakan oleh siswa kelas XI MA.

Buku Siswa pelajaran bahasa Arab untuk kelas XI kurikulum 2013 KMA Nomor 183 yang diterbitkan Kementerian Agama Indonesia menjadi objek kajian penelitian dikarenakan remaja (16-18)tingkat SMA (Sekolah Menengah Atas) yang berpikirnya sudah mengarah sifat hipotesis, abstrak, sistematis dan ilmiah dalam memecahkan masalah. Kebijakan yang diambil oleh Kementerian Agama terkait menyediakan buku pelajaran sendiri pada kurikulum 2013 terbaruyang dipakai dalam pembelajaran di lingkup Madrasah menjadi sesuatu yang menarik untuk dikaji dari berbagai pandangan mengingat pentingnya peran dan fungsi buku ajar dalam suatu pembelajaran dan dalam kesempatan ini kajian dilakukan dalam hal muatan keindonesiaan Indonesia. Penelitian ini dilakukan karena masih minim penelitian terkait dengan muatan budaya.Penelitian tentang muatan budaya dalam buku ajar bertujuan memberikan pemahaman tentang keindonesiaan budaya indonesia dalam buku ajar khususnya buku ajar bahasa Arab pada tingkat SMA kelas XI.

Penelitian ini sangat perlu dilakukan karena mengingat siswa atau murid yang mempelajari bahasa arab kurang memahami budaya-budaya Indonesia yang ada didalam buku ajar bahasa. Peserta didik harus lebih mengetahui 
budayanya sendiri dahulu sebelum mengenal dan memahami budaya-budaya bahasa target (bahasa Arab).

\section{B. Pembahasan}

1. Muatan Budaya dalam Buku Ajar

Definisi budaya banyak diartikan sebagai sesuatu yang kompleks yang melingkupi kehidupan manusia sebagai hasil cipta, rasa dan karsa manusia. Soerjono Sukanto, dengan mengutip E.B. Taylor, mengungkapkan bahwa kebudayaan adalah "Kompleks yang mencakup pengetahuan, kepercayaan, kesenian, moral, adat-istiadat dan lain kemampuan-kemampuan serta kebiasaan-kebiasaan yang didapatkan oleh manusia sebagai anggota masyarakat". Dalam kaitan ini budaya sering berkaitan dengan pencapaian dan penciptaan terhadap sebuah karya, baik berupa adat, kebisaaan, sains, teknologi, seni, agama dan lain sebagainya yang tersimbolkan dalam banyak bentuk. Secara sistematik, unsur-unsur kebudayaan dirumuskan menjadi; system religi dan keagamaan, system organisasi kemasyarakatan, system pengatahuan, bahasa, kesenian, system mata pencaharian, dan system teknologi dan peralatan. Namun secara keseluruhan, budaya adalah produk masyarakat.

Sesuai dengan tujuan untuk bisa berinteraksi dengan masyarakat dari ruang budaya sasaran Indonesia, maka akses yang dapat digunakan adalah kearifan lokal dengan sumber belajar otentik. Jika kegiatan pembelajaran itu adanya di tatar Sunda, misalnya, maka pintu masuk pertamanya dapat berupa unsur-unsur budaya Sunda yang ada. Di sini bukan berarti bahwa bahan ajar yang digunakan harus berbahasa Sunda, melainkan bahwa di dalam bahan ajar tersebut seyogyanya diakomodir „muatan lokal“ yang dapat menggiring pembelajar ke dalam suasana Sunda.

Teori Prihatini (2015) tentang "konten budaya lokal" sebagai berikut; konten budaya lokal berisikan tindak laku masyarakat lokal 
sebagaimana nilai adat dan karya-karya lokal seperti: cerita rakyat, bahasa daerah,namadan gelar lokal, tarian tradisional, instrumen musik tradisional dan artefak.

2. Metode Penelitian

Penelitian ini berupa penelitian kualitatif menggunakan pendekatan linguistik yang berfokus pada muatankearifan local budaya Indonesia. Sumber data primer dalam penelitian adalah buku bahasa Arabkelas XI Kementerian Agama Republik Indonesia KMA Nomor 183 Tahun 2019Peneliti menggunakan penelitian kepustakaan yang didasarkan atas pencarian literature yang berkaitan dengan permasalahan yang akan dibahas. Data dalam penelitian kepustakaan ini didapat dengan cara menggali dan menulusuri jurnal, artikel, akses internet, majalah, buku-buku. Sementara pendekatan dalam penelitian ini menggunakan pendekatan kualitatif, karena data yang telah dikumpulkan lebih menekankan pada data yang bersifat kualitatif.

Penelitian ini bersifat deskriptif analitis yang dilakukan dengan cara mengumpulkan data yang berkaitan dengan buku ajar bahasa Arab, menafsirkan data yang diperoleh, kemudian mengadakan analisis dan interpretasi terhadap data tersebut. Peneliti memverifikasi pada bagianbagian dari literatur yang dapat dianalisis.

Peneliti menggunakan metode analisis isi untuk tahapan analisis data dalam penelitian ini, karena akan memanfatkan langkah-langkah untuk mengambil kesimpulan dari buku bahasa Arabkelas XI Kementerian Agama Republik Indonesia KMA Nomor 183 Tahun 2019. Hal ini didasarkan pada Weber dan Meleong mengatakan bahwa kajian ini adalah metodologi peneitian yang memanfaatkan seperangkat prosedur untu menarik kesimpulan yang benar dari sebuah buku atau dokumen. Untuk mendapatkan gambaran tentang kondisi dari adaptasi bahasa budaya Indonesia dalam buku bahasa Arabkelas XI Kementerian 
Agama Republik Indonesia KMA Nomor 183 Tahun 2019, data nanti akan dirinci, dipilih-pilih, diklasifikasi, dibandingkan kemudian hasilnya akan dicocokkan dengan teori tentang bagaimana seharusnya kondisi unsurunsur tersebut. Data yang sudah terkumpul dengan metode diatas, peneliti kemudian menganalisa data tersebut dengan menggunakan analisis deskriptif kualitatif, tanpa menggunakan anaisis kuantitatif.

Keindonesiaan dengan sumber belajar yang otentik adalah salah satu akses yang dapat digunakan yang bertujuan untuk bisa berinteraksi dengan masyarakat dari ruang budaya sasaran Indonesia. Oleh karena itu salah satu unsur yang menjadi sarana untuk mengungkapkan keindonesiaan adalah menggunakan bahasa. Selain itu juga bahasa menjadi media penyebaran yang digunakan untuk menyebarkan keindonesiaan daerah satu ke daerah lain.

Materi yang terdapat dalam buku ajar bahasa Arab Madrasah Aliyah kelas XI cetakan Kementerian Agama nomor 183 tahun 2019 terdiri 6 bab: Bab 1 (التسوق), Bab 2 (الصحة), Bab 3 (السفر), Bab 4 (الحجر) (والعمرة), Bab 5 (تكنولوجيا الإعلاموالاتصيال), dan Bab 6 (الأديان في الإندونيسيا). Berdasarkan hasil analisis yang telah dilakukan, muatan keindonesiaan dalam buku ajar bahasa Arab cetakan Kementerian Agama KMA nomor 183 tahun 2019 yang didalamnya terdapat materi berupa teks yang bertemakan "Masjid Istiqlal" hanya di temukan di bab 6. Penelititelah menganalisis teks tersebut bahwa ada muatan keindonesiaan budaya Indonesia di dalamnya. Berikut adalah isi dari teks yang membahas tentang hal tersebut.

3. Unsur-unsur Budaya dalam Buku ajar Bahasa Arab MA Kelas XI Cetakan Kementerian Agama Nomor 183 Tahun 2019.

Peneliti dalam hal ini mendasarkan pembahasan pada teori sebelumya yaitu Koentjaraningrat (2015: 2) berpendapat bahwa 
terdapat tujuh unsur kebudayaan, yakni : 1) Sistem religi dan upacara, 2) Sistem dan organisasi kemasyarakatan, 3) sistem pengetahuan, 4) bahasa, 5) kesenian, 6) sistem mata pencaharian hidup, 7) sistem teknologi dan peralatan.

a. Teks Muatan Keindonesiaan

الأديَانَ فِ إنْدُوْينْسِيًَا

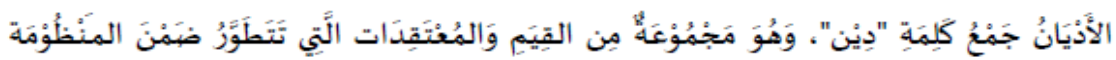

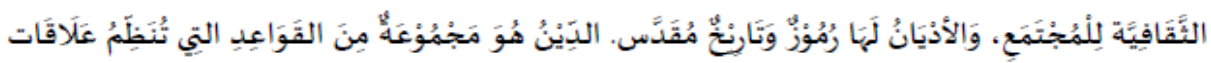

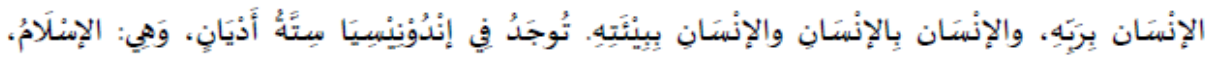

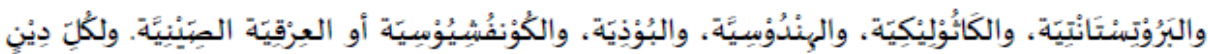

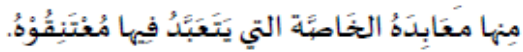

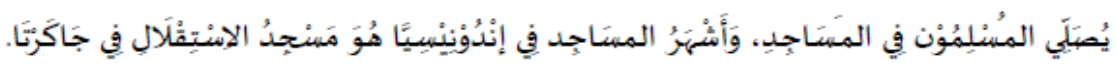

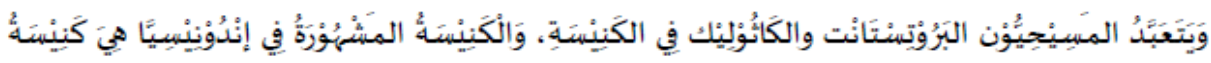

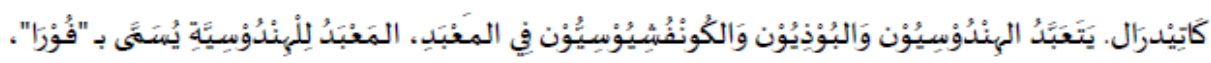

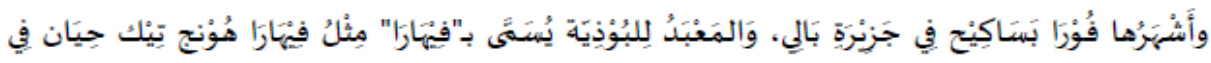

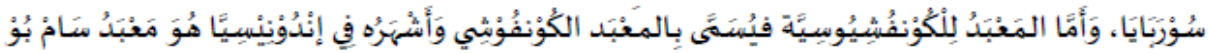
كُوْنج فِ سَمَمَارَانُج.

Gambar 1.Teks Materi Buku Bahasa Arab Madrasah Aliyah Kelas XI Kementerian Agama Nomor 183 Tahun 2019 halaman 91

\begin{tabular}{|c|c|}
\hline النص & \\
\hline 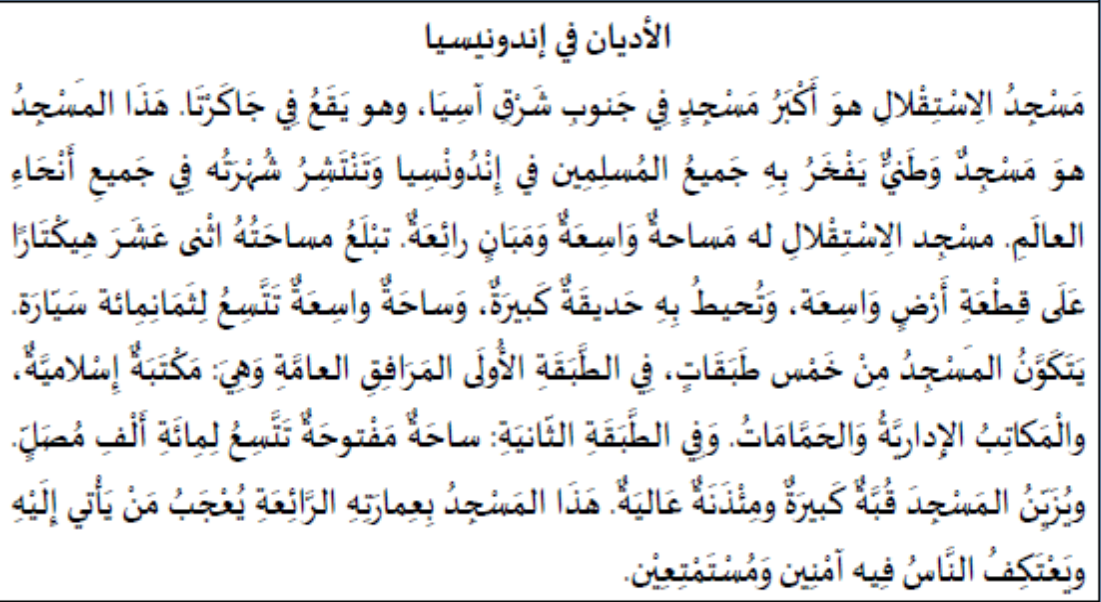 & السادس \\
\hline
\end{tabular}


Berikut ini terjemahan Indonesia dari teks muatan keindonesiaan gambar 2 .

\section{Masjid Istiqlal}

Masjid Istiqlal adalah masjid terbesar di Asia Tenggara yang terletak di Jakarta. Masjid ini merupakan masjid nasional kebanggan seluruh kaum muslim Indonesia dan juga terkenal di seluruh alam. Masjid Istiqlal mempunyai halaman yang luas dan beberapa bangunan yang indah. Area masjid Istiqlal mencapai 12 Hektar. Arenya meliputi taman yang besar dan halaman luas yang memuat 800 mobil. Masjid ini terdiri dari 5 lantai, lantai satu fasilitas-fasilitas umum : perpustakaan islam, meja-meja, kantor-kantor dan beberapa kamar mandi. Lantai dua : halaman terbuka yang memuat ratusan ribu jamaah. Masjid ini dihiasi kubah besar dan menara yang tinggi. Masjid dengan bangunan yang indah ini membuat orang yang datang itu takjub dan memberikan rasa aman dan senang.

b. Sistem Religi dan Upacara Keagamaan

Dalam hal ini materi bab VI bahasa Arab madrasah Aliyah kelas XI cetakan Kementerian Agama nomor 183 tahun 2019 mengandung unsur religi yang mana masjid Istiqlal ini adalah tempat yang digunakan oleh kaum muslim untuk melaksanakan kegiatan ibadah. Selain itu juga masjid Istiqlal ini menjadi tempat untuk melaksanakan kegiatan upacara-upacara keagamaan seperti, pengajian rutin Islam setelah solat, pembacaan Al-Qur'an berjamaah, dan bimbingan pembacaan syahadat untuk orang yang mau Islam.

Gambar diatas menunjukkan bahwa masjid istiqlal merupakan salah satu tempat ibadah yang ada di Indonesia yang digunakan untuk melaksanakan ibadah. Pembangunan masjid ini diprakarsai oleh Presiden Republik Indonesia saat itu, Ir.Soekarno pada 24 
Agustus 1951. Arsitek Masjid Istiqlal adalah Frederich Silaban(Jannah, 2017).

c. Sistem dan Organisasi Kemasyarakatan

Sistim organisasi adalah bagian kebudayaan yang berisikan semua yang telah dipelajari yang memungkinkan bagi manusia mengkoordinasikan perilakunya secara efektif dengan tindakantindakan-tindakan orang lain (Syani, 1995).Dalam hal ini materi bab VI bahasa Arab madrasah Aliyah kelas XI cetakan Kementerian Agama nomor 183 tahun 2019 mengandung unsurorganisasi kemasyarakatan yang mana masjid ini menjadi pedoman dan teladan pengelolaan masjid di Indonesia, sehingga harus menjadi contoh dan model dalam pengelolaan masjid secara nasional. Dalam konsep pengelolaan masjid yang ideal, masjid tidak hanya berfungsi sebagai tempat ibadah, tetapi juga harus mejadi tempat pembinaan umat melalui berbagai macam kegiatan. Salah satu kegiatan yang sangat penting adalah pendidikan untuk pembinaan masyarakat atau umat baik pendidikan formal maupun non formal. Telah diselenggarakan pendidikan formal di Masjid Istiqlal yang terdiri dari jenjang pendidikan: Kelompok bermain dan Raudhatul Athfal, Madrasah Ibtidaiyah (MI) dan Madrasah Tsanawiyah (MTs).

Sebagai masjid terbesar di Kawasan Timur Asia (Asia Tenggara dan Asia Timur), Masjid Istiqlal menarik perhatian wisatawan dalam dan luar negeri, terutama wisatawan muslim yang datang dari berbagai penjuru Indonesia ataupun wisatawan Muslim dari luar negeri. Pengunjung muslim dapat langsung masuk dan berbaur dengan jemaah untuk menunaikan salat berjemaah. Wisatawan non-Muslim diperbolehkan berkunjung dan memasuki masjid ini, setelah sebelumnya mendapat pembekalan informasi mengenai Islam dan Masjid Istiqlal. Pengunjung non-Muslim harus mengikuti tata cara mengunjungi masjid seperti melepaskan alas 
kaki serta mengenakan busana yang sopan dan pantas. Misalnya pengunjung tidak diperkenankan mengenakan celana pendek atau pakaian yang kurang pantas (busana lengan pendek, kaus kutang atau tank top). Pengunjung yang mengenakan celana pendek biasanya dipinjamkan sarung, sedangkan pengunjung wanita diminta mengenakan kerudung. Meskipun demikian bagian yang boleh dikunjungi kaum non-Muslim terbatas dan harus didampingi pemandu. Misalnya pengunjung non-Muslim (kecuali tamu negara atau VVIP) tidak diperkenankan memasuki lantai pertama ruang utama tempat mihrab dan mimbar, tetapi diperbolehkan melihat bagian dalam ruangan ini dari balkon lantai kedua. Selebihnya pengunjung non-Muslim boleh mengunjungi bagian lain seperti pelataran terbuka, selasar, kaki menara dan koridor masjid.

d. Sistem Pengetahuan

Spradlye (dalam Kalangie, 1994) menyebutkan, bahwa pengetahuan budaya itu bukanlah sesuatu yang bisa kelihatan secara nyata, melainkan tersembunyi dari pandangan, namun memainkan peranan yang sangat penting bagi manusia dalam menentukan perilakunya. Pengetahuan budaya yang diformulasikan dengan beragam ungkapan tradisional itu sekaligus juga merupakan gambaran dari nilai-nilai budaya yang mereka hayati.

Dalam hal ini materi bab VI bahasa Arab madrasah Aliyah kelas XI cetakan Kementerian Agama nomor 183 tahun 2019 mengandung unsur pengetahuan yang manaperpustakaan Islam Istiqlal, walaupun belum bisa mewakili jumlah besarnya koleksi buku seperti perpustakaan-perpustakaan Islam yang besar lainnya, mewakili fungsinya sebagai pusat keilmuan Islam. Perpustakaan Islam sendiri sudah mulai berkembang di Indonesia. Hampir di setiap masjidmasjid besar di Ibukota, telah dilengkapi dengan sarana perpustakaan. 
Berbeda dengan Kubah masjid Istiqlal yang mencerminkan yang terbuat dari stainles steel, kubah Al-Jami' al-Aqsha yang terletak di Yerussalam ini menunjukkan ciri arsitektur Islam awal. Kubah yang asli dibangun oleh Abdul Malik bin Marwan, tetapi sekarang sudah tidak ada lagi sisanya. Bentuk kubah seperti yang ada saat ini awalnya dibangun oleh Ali azh-Zhahir dan terbuat dari kayu yang disepuh dengan lapisan enamel timah. Pada tahun 1969, kubah dibangun kembali dengan menggunakan beton dan dilapisi dengan aluminium yang dianodisasi sebagai ganti dari bentuk aslinya yaitu lapisan enamel timah yang berusuk. Pada tahun 1983, aluminium yang menutupi bagian luar diganti lagi dengan timah untuk menyesuaikan dengan desain asli Azh-Zhahir.

Kubah Al-Jami' al-Aqsha adalah salah satu dari sedikit masjid dengan kubah yang dibangun di depan mihrab selama periode Umayyah dan Abbasiyah, contoh lainnya adalah Masjid Umayyah di Damaskus (715) dan Masjid Besar Sousse (850).Interior kubah dicat menurut dekorasi era abad ke-14. Pada kebakaran tahun 1969, cat dekoratif itu rusak dan sempat dianggap sudah tidak dapat diperbaiki lagi. Namun dengan menggunakan teknik trateggio, yaitu sebuah metode yang menggunakan garis-garis vertikal halus untuk membedakan daerah yang direkonstruksi dengan daerah yang asli, akhirnya dapat diperbaiki kembali dengan sempurna.

e. Bahasa

Dalam hal ini materi bab VI bahasa Arab madrasah Aliyah kelas XI cetakan Kementerian Agama nomor 183 tahun 2019 mengandung unsurbahasa yang mana bahasa yang dominan digunakan dalam ruang lingkup masjid ini adalah bahasa Indonesia, kemudian Arab setelah itu Inggris. Bahasa adalah alat atau perwujudan budaya yang digunakan manusia untuk saling berkomunikasi atau berhubungan, baik lewat tulisan, lisan, ataupun gerakan (bahasa isyarat), dengan 
tujuan menyampaikan maksud hati atau kemauan kepada lawan bicaranya atau orang lain. Melalui bahasa, manusia dapat menyesuaikan diri dengan adat istiadat, tingkah laku, tata krama masyarakat, dan sekaligus mudah membaurkan dirinya dengan segala bentuk masyarakat. Bahasa memiliki beberapa fungsi yang dapat dibagi menjadi fungsi umum dan fungsi khusus.

Fungsi bahasa secara umum adalah sebagai alat untuk berekspresi, berkomunikasi, dan alat untuk mengadakan integrasi dan adaptasi sosial. Sedangkan fungsi bahasa secara khusus adalah untuk mengadakan hubungan dalam pergaulan sehari-hari, mewujudkan seni (sastra), mempelajari naskah-naskah kuno, dan untuk mengeksploitasi ilmu pengetahuan dan teknologi (Koentrajaningrat, 2002). Sesuatu yang berawal dari hanya sebuah kode, tulisan hingga berubah sebagai lisan untuk mempermudah komunikasi antar sesama manusia. Bahkan sudah ada bahasa yang dijadikan bahasa universal seperti bahasa Inggris.

f. Kesenian

Sebagai makhluk yang mempunyai cita rasa tinggi, manusia menghasilkan berbagai corak kesenian mulai dari yang sederhana hingga perwujudan kesenian yang kompleks. Kesenian yang meliputi: seni patung/pahat, seni rupa, seni gerak, lukis, gambar, rias, vocal, musik/seni suara, bangunan, kesusastraan, dan drama (Koentrajaningrat, 2002).Dalam hal ini materi bab VI bahasa Arab madrasah Aliyah kelas XI cetakan Kementerian Agama nomor 183 tahun 2019 mengandung unsurkesenian yang mana masjid ini memiliki seni yang unik dari kubahnya, Dengan diameter $45 \mathrm{~m}$, terbuat dari kerangka baja antikarat dari Jerman Barat dengan berat 86 ton, sementara bagian luarnya dilapisi dengan keramik. Diameter 45 meter merupakan simbol penghormatan dan rasa syukur atas kemerdekaan Bangsa Indonesia pada tahun 1945 sesuai dengan nama Istiqlal itu sendiri. Bagian bawah sekeliling kubah terdapat 
kaligrafi Surat Yassin yang ditulis oleh K.H Fa'iz seorang Khatthaath senior dari Jawa Timur.

Dari luar atap bagian atas kubah dipasang penangkal petir berbentuk lambang Bulan dan Bintang yang terbuat dari stainless steel dengan diameter 3 meter dan berat 2,5 ton. Dari dalam kubah di topang oleh 12 pilar berdiameter 2,6 meter dengan tinggi 60 meter, 12 buah pilar ini merupakan simbol angka kelahiran nabi Muhammad SAW yaitu 12 Rabiul Awal tahun Gajah atau 20 April 571 M.

g. Sistem teknologi dan peralatan

Dalam hal ini materi bab VI bahasa Arab madrasah Aliyah kelas XI cetakan Kementerian Agama nomor 183 tahun 2019 mengandung unsurteknologi dan peralatan yang mana masjid ini mempunyai parkiran seluas 2,15 Ha, yang dapat menampung kurang lebih 800 kendaraan sekaligus melalui 7 buah pintu gerbang yang ada. Kualitas pengaspalan untuk halaman, parkir dan jalan dibuat dengan methode pengaspalan kelas satu.

Ada sejumlah keunikan yang dimiliki Istiqlal. Sebagai masjid terbesar di Indonesia,Arsitektur Istiqlal terbilang simple dan cukup modern saat dibangun pada eranya ketika itu. Bila pada umumnya sebuah masjid memiliki desain yang menakjubkan pada ruang imam, hal itu justru tidak terlihat pada Istiqlal melainkan pada kubah. Kubah yang terbuat dari stainles steel ini sangat detail. Masjid Istiqlal juga dilengkapi dengan plaza terbuka. Bentuk masjid beserta lanskapnya saat itu belum lazim di Indonesia, karena masjid di Indonesia saat itu masih berbentuk atap tumpang atau kubah tanpa plaza.

Untuk unsur mata pencaharian hidup, peneliti belum menemukan adanya data yang menerangkan tentang keindonesiaan budaya Indonesia dalam unsur tersebut 
4. Nilai-Nilai Sosial Budaya yang Termuat dalamBuku ajar Bahasa Arab MA Kelas XI Cetakan Kementerian Agama Nomor 183 Tahun 2019.

Teori Cheng (2002: 32-33) tentang; Theory of tree/teori pohon yang terfokus pada akar budaya kepada masyarakat global sebagaiman yang diproses pada pengembangan budaya itu sendiri, theory of cristal/teori kristal, Menurut teori ini, desain kurikulum dan pengajaran adalah untuk mengidentifikasi inti kebutuhan dan nilai-nilai lokal sebagai benih mendasar untuk mengakumulasi pengetahuan dan sumber daya global yang relevan untuk pendidikan. Dalam pendidikan global, pemahaman tentang struktur pengetahuan lokal adalah dasar yang diperlukan bagi siswa untuk mengakumulasi pengetahuan dan kebijaksanaan global termasuk didalamnya ada keterkaitan antara budaya dan pembelajaran bahasa. Hasil pendidikan yang diharapkan adalah mengembangkan orang lokal yang tetap orang lokal dengan pengetahuan global dan dapat bertindak secara lokal dan berpikir secara lokal dengan teknik global yang meningkat.

Pada umunya, terdapat banyak hal dan beraneka ragam muatan social-budaya dalam penampilan buku teks tergantung pada kreatifitas penulisnya. Ada beberapa isu sentral yang menjadi focal points dalam penelitian yakni:

a. Nomenclature (penggunaan nama dan/atau istilah bagi orang, kota dan daerah)

b. Address terms (sapaan terhadap orang/atau sistem kekerabatan dalam keluarga)

c. Cultural info (informasi budaya penutur asli yang perlu diketahui oleh pelajar)

d. Cultural sites (obyek social-budaya)

e. Socio-cultural tradition (tradisi social-budaya dan teknologi dala bahasa target)

f. Etiquette (etiket social dan sopan santun dalam bahasa target) 
Beberapa buku teks pelajaran bahasa kedua (dan/atau asing) yang telah dimanfaatkan sebagai obyek penelitian ini diseleksi secara acak sesuai dengan ketersedian dan kebutuhan penelitian

a. Nomenclature:hal ini berkaitan dengan penggunaan nama atau istilah bagi orang, kota dan daerah. Misalnya buku teks pelajaran bahasa Arab MA kelas XI menyajikan muatan social budaya khas Indonesia. Nama-nama orang dalam buku teks itu adalah Fatih, Muhammad, Hasan, Fatimah, Toni (p. 66). Nama daerah dan kota yang dimuat adalah Jakarta, Bali, Pantai kuta (p. 38), Masjid istiqlal (p. 91). Di negeri ini, para penyusun buku teks harus mengikuti kurikulum nasional yang sudah dibuat oleh pihak pemerintah. Oleh sebab itu, mereka akan cenderung membuat buku teks yang sesuai dengan ideology Negara dan menghindari muatan social-budaya asing yang tercemin dalam bahasa target yang diajarkan.

b. Address terms:menurut teori, sapaan terhadap orang/atau sistem kekerabatan dalam keluarga berkaitan dengan penggunaan pronominal kedua baik tunggal atau jamak tergantung pada bahasa bersangkutan. Misalnya, kata “يَّا سيّدي" yang artinya tuanku (p. 21). Kata tersebut dalam sebuah percakapan di buku teks ini digunakan untuk menyapa orang yang memiliki jenis kelamin laki-laki. Hal ini juga dilakukan oleh orang Indonesia, ketika bertemu dengan orang laki-laki dan menyapanya dengan menggunakan kata "pak".

c. Cultural info:menurut teori, informasi budaya penutur asli yang perlu diketahui oleh pelajar adalah bahan pembicaraan yang perlu disajikan dalam buku teks. Misalnya yang ada di buku teks ini sudah gambar bepergian (السفر: p. 38) menampilkan pesawat terbang yang bernuansa Arabdengan pramugari yang berjilbab khas Arab.

d. Cultural sites: menurut teori, Tempat yang memiliki obyek socialbudaya yang sangat digemari oleh penulis buku teks pelajaran. 
Contohnya yang paling mencolok adalah masjid istiqlal di kota Jakarta Negara Indonesia (p. 91) dan pantai kuta kota Bali (p. 38).

e. Socio-cultural tradition: menurut teori, tradisi social-budaya dalam bahasa target. seperti contoh (p. 46)

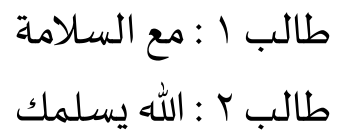

Orang pertama mengucapkan Kata "مع السلامة" yang artinya "sampai jumpa atau semoga keselamatan menyertaimu" kemudian dijawab oleh orang kedua "الله يسلمك" yang artinya semoga Allah selalu memberikan keselamatan untukmu. Hal ini sudah menjadi budaya orang Arab yang mana saling mendoakan ketika bertemu maupun berpisah untuk menjaga hubungan satu sama lain.

f. Etiquette: menurut teori,etiket social dan sopan santun dalam bahasa target yang ada di buku teks ini misalnya (p. 21)

$$
\text { : أهلا وسهلا يا سيدي، أي خذمة ؟ أريد أن أقابل الطبيب. }
$$

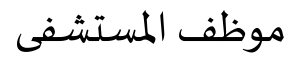

Peryataan tersebut menggambang pata "أي خذمة yang artinya ada yang bisa saya bantu. hal ini merupakan etika sopan santun dalam bahasa target dari segi budaya Arab maupun Indonesia.

\section{SIMPULAN}

Berdasarkan hasil penelitian dapat disimpulkan bahwa muatan keindonesiaan budaya Indonesia yang terdapat di dalam buku bahasa Arab Madrasah Aliyah cetakan Kementrian Agama Republik Indonesia nomor 183 tahun 2019 hanya ditemukan pada bab 6. Unsur-unsur budaya yang terdapat di dalam buku bahasa Arab Madrasah Aliyah cetakan Kementrian Agama Republik Indonesia nomor 183 tahun 2019 teridentifikasi ada 6yang sesuai 
dariunsur budaya yaitu, a) sistem religi dan upacara keagamaan, b) sistem dan organisasi kemasyarakatan, c) sistem pengetahuan, d) kesenian, dan e) Sistem teknologi dan peralatan. 


\section{DAFTAR PUSTAKA}

Al-Aqsa Mosque Restoration Archnet Digital Library.

Arifah, Fatma dkk, Cultural Values Of Women And Marriage In Al-Arabiyyah Bayna Yadaik and Al-Kitab Fi Ta'allum Al-Arabiyyah, Arabi: Journal of Arabic Studies, $5(1), 2020,11-24$

Elad, Amikam. 1995. Medieval Jerusalem and Islamic Worship Holy Places, Ceremonies, Pilgrimage BRILL.

Elayyan, Ribhi Mustafa. 1990. "The history of the Arabic-Islamic Libraries: 7th to 14th Centuries". International Library Review. 22 (2): 119 135. doi:10.1016/0020-7837(90)90014-7.

Gonen, Rivka. 2003 Contested Holiness KTAV Publishing House.

Koentjaraningrat. 2015. Pengantar Ilmu Antropologi. Jakarta: Rineka Cipta.

Marfai, Muh Aris. 2013. Pengantar Etika Lingkungan dan Keindonesiaan. Yogyakarta: GadjahMada University Press.

Moleong, Lexy. J. 1992. Metode Penelitian Kualitatif. Bandung: PT Remaja Rosda karya.

Nurhidayati, Laily. Pengembangan Buku Ajar Bahasa Arab Berbasis Keindonesiaan Budaya Solo Untuk Siswa Kelas XI MA Di Kota Solo, Skripsi, Fakultas Bahasa dan Seni Universitas Negeri Semarang, (Semarang: 2019)

Olajide, Stephen Billy. 2010. ,A Critical Assessment of the Cultural Content of Two Primary English Textbooks Used in Nigeria', Journal of Language Teaching and Research, Vol. 1, No. 5, 656-661.

Orr, Make. 2014. Ideology for second Language Teachers, Arab WorldEnglish Journal, Vol. 5, No. 4, 3-13.

Purwoko, Herudjati, “Muatan Sosial-Budaya dalam Buku Teks Pelajaran Bahasa Asing" Parole, Vol. 1, Oktober 2010.

Shofiana, Laila. Muatan Budaya Dalam Buku Teks Pelajaran Bahasa Arab Untuk Siswa Madrasah Aliyah Kelas XI Kurikulum 2013 Terbitan Kementrian Agama, Tesis. Pendidikan Islam, UIN Sunan Kalijaga(Yogyakarta: 2016) 
Sorongan, dkk, "An Analysis of Local and target Culture Integration in English Textbooks" LINGUA: Jurnal Bahasa dan Sastra, Vol.15, No.1, Desember 2014, 29-34.

Sugiyono. 2006. Metode Penelitian Pendidikan, Pendekatan Kuantitatif, Kualitatif dan $R \& D$. (Bandung: Alfabeta).

Yusari, Nur Indah. 2012. “Konsep Privasi Masalah Lintas Budaya Dalam Pengajaran Bahasa Indonesia Untuk Penutur Asing".Prosiding Seminar Internasional Multikultural \& Globalisasi. Fakultas Ilmu Pengetahuan Budaya Universitas Indonesia. 